\title{
USE OF AMMONIUM PERSULPHATE FOR REVEALING THE MACROSTRUCTURE OF IRON AND STEEL
}

\author{
By Henry S. Rawdon
}

CONTENTS

I. Introduction . . . . . Page

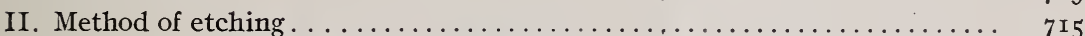

I. Principles underlying the action ................. $7^{\text {I } 5}$

2. Method of application . . . . . . . .

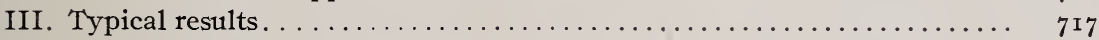

I. Crystalline heterogeneity ..................... 7 I 7

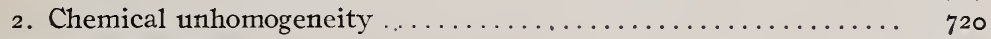

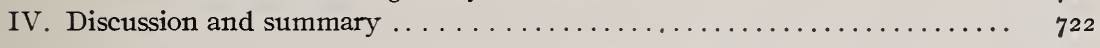

\section{INTRODUCTION}

In the metallographic examination of any metallic material a study of the macrostructure occupies a prominent and important place. It is generally necessary to use special reagents for revealing the different structural features and many such etching solutions have been described and their use is now a routine matter in most metallographic laboratories. One of the most widely used reagents for revealing the macrostructure of copper alloys, particularly the brasses and bronzes, is ammonium persulphate. This has also been suggested as a means for revealing the microstructure of iron ${ }^{1}$ though not used to any appreciable extent. The advantages of its use as a macroscopic etching medium for iron and steel appear to have been very largely overlooked. In the following discussion the use of ammonium persulphate for this purpose and the structural features which it reveals in a particularly striking manner are pointed out.

\section{METHOD OF ETCHING}

\section{PRINCIPLES UNDERLYING THE ACTION}

Ammonium persulphate is a very strong oxidizing agent and decomposes readily when dissolved in water. According to

${ }^{1} \mathrm{~J}$. Czochralski, Principles of Etching Phenomena and Metallographic Etching Processes; Stahl und Eisen; 35, No. II, p. 1073, 1915.

$$
13509^{\circ}-20
$$


Treadwell, ${ }^{2}$ the fundamental reaction which occurs when water is added to a persulphate is represented by the following equation:

$$
\text { (I) } 2\left(\mathrm{NH}_{4}\right)_{2} \mathrm{~S}_{2} \mathrm{O}_{8}+2 \mathrm{H}_{2} \mathrm{O}=2\left(\mathrm{NH}_{4}\right)_{2} \mathrm{SO}_{4}+2 \mathrm{H}_{2} \mathrm{SO}_{4}+\mathrm{O}_{2} \text {. }
$$

A further reaction occurs with ammonium persulphate by which some of the ammonia is oxidized to the form of nitrate.

(2) $8\left(\mathrm{NH}_{4}\right)_{2} \mathrm{~S}_{2} \mathrm{O}_{8}+6 \mathrm{H}_{2} \mathrm{O}=7\left(\mathrm{NH}_{4}\right)_{2} \mathrm{SO}_{4}+9 \mathrm{H}_{2} \mathrm{SO}_{4}+2 \mathrm{HNO}_{3}$.

The above equations indicate that the general effect of ammonium persulphate as an etching medium is that of a dilute acid, the action of which is intensified by the presence of free oxygen. In a previous article ${ }^{3}$ the importance of available oxygen in metallographic etching reagents has been pointed out. It may be easily shown also that aqueous solutions of ammonium sulphate have a considerable etching action upon segregated steels, hence it is very probable that the sulphate which is formed as one of the reaction products aids somewhat in the etching action of the persulphate solution.

\section{METHOD OF APPLICATION}

On account of the readiness with which ammonium persulphate crystals decompose when water is added to them, the etching solution must always be freshly prepared just before use. One gram of the salt in $10 \mathrm{~cm}^{3}$ of water was found to give excellent results. If desired the amount of persulphate may be increased considerably, for instance, to $2 \mathrm{~g}$ in $10 \mathrm{~cm}^{3}$ of water. The salt dissolves gradually in the water, hence the exact concentration of the etching solution can not be stated.

The etching is best carried out by means of a cotton swab which has been soaked in the solution. The swab is rubbed over the face of the specimen, considerable pressure being used. A fine polish of the specimen is unnecessary; usually it is sufficient to finish the face on fine emery paper-for instance, $O O$ French emery paper. The dark oxide film which often forms on the freshly etched face of the specimen if it is allowed to stand in the air without drying for a few minutes can be easily removed by a fresh application of the etching solution on the cotton swab. An etching period of from $\mathrm{I}$ to 2 minutes is usually sufficient.

\footnotetext{
2 Treadwell, Analytical Chemistry, p. 595.

${ }^{3}$ Henry S. Rawdon and Marjorie G. Lorentz, B. S. Sci. Papers, No. 399.
} 
One of the advantages of the method of etching described is the readiness of control of the process. The surface is constantly under observation and the etching can be stopped at any instant when the structure is distinctly revealed, by holding the specimen in a running stream of water.

The photographing of the etched surface of the specimen is best carried out while the specimen is immersed in water, alcohol, or light oil. In case the specimen is too large for immersion, the surface may be rubbed with oil or glycerin in order to increase the brilliancy of the etch pattern. In general, this device is helpful in the photographing of all macroscopic specimens.

\section{TYPICAL RESULTS}

In the following figures a few illustrations, chosen from a considerable number of specimens etched by this method, are given to show the results obtained by the use of the reagent. They also illustrate the fact that in some cases features are revealed by the persulphate which would be missed entirely if sole dependence was placed upon some other reagent.

\section{CRYSTALLINE HETEROGENEITY}

Ammonium persulphate is most admirable for revealing crystalline heterogeneity of any material. This is illustrated by Fig. I, which shows sections of two fusion welds made by the oxyacetylene process. Etching with an aqueous solution of copper ammonium chloride and with alcoholic nitric acid both failed to reveal clearly the pronounced grain growth which accompanied the welding process and which influences to a very marked degree the mechanical properties of the weld. This is very clearly revealed by the use of the persulphate. A single type of etching reagent should not be depended upon for completely revealing the macrostructure of any specimen. Each reagent used, as illustrated in Fig. I, reveals certain characteristic features of the material under observation. It appears, however, that the persulphate solution revealed more features in a single etching than did either of the other two in this particular case.

In Fig. 2 a specimen of commercial wrought iron is shown and the results obtained by the use of ammonium persulphate may be compared with those of four other reagents in common use. Although the characteristic "streaky" condition is revealed by several, the peculiar variations in the crystalline condition are 

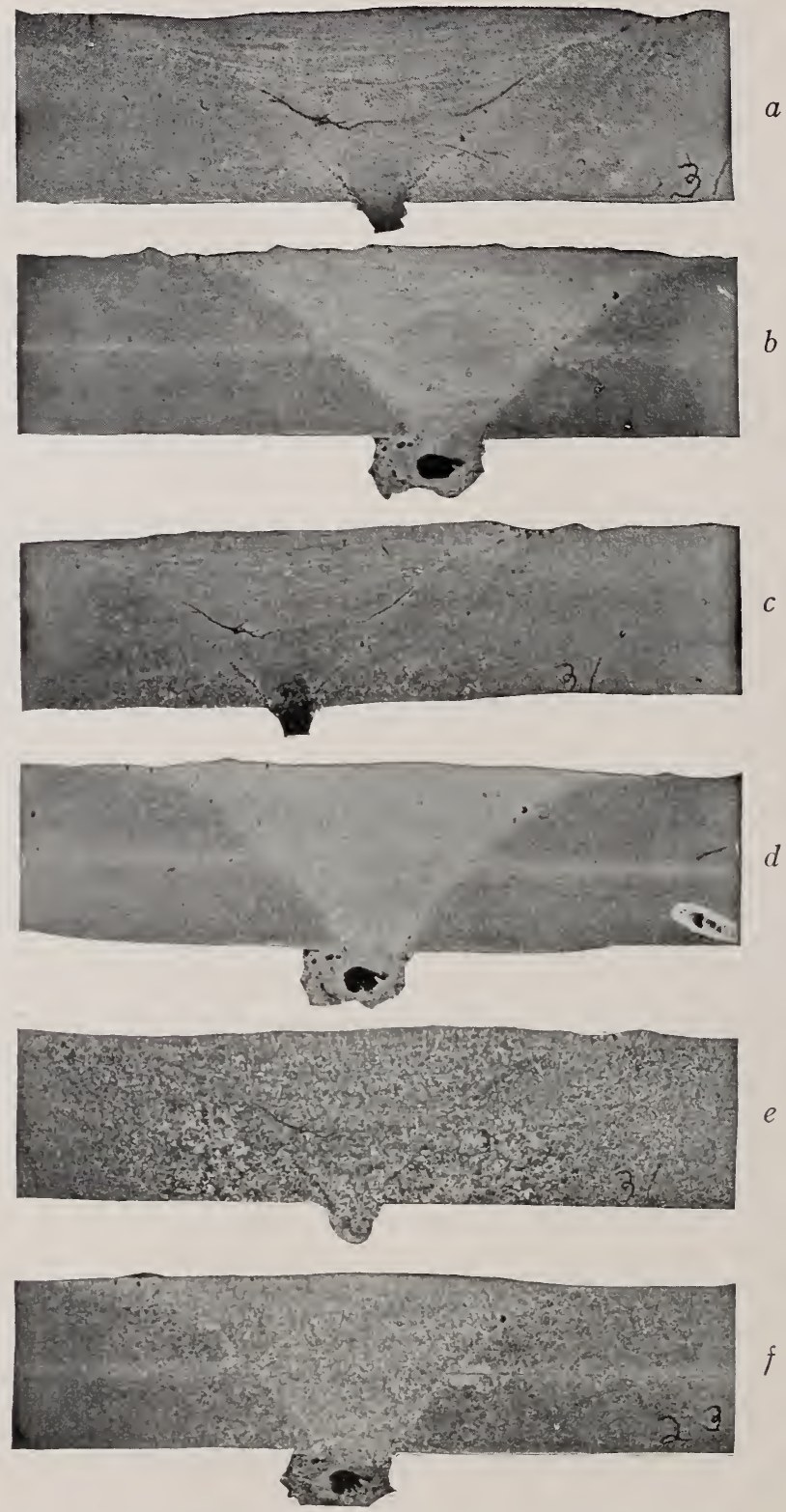

FIG. I.-Crystalline heterogeneity of fusion welds of steel as revealed by different etching reagents. $X I$

The same two welds were used for each of the three etching reagents. Etching reagents: $a$ and $b$, Copper ammonium chloride (Heyn's reagent); $c$ and $d, 2$ per cent alcoholic nitric acid; $e$ and $f$, aqueous solution of ammonium persulphate 
revealed only by the persulphate. In Fig. 3 the same specimen is shown at a slightly higher magnification in order to reveal the crystalline pattern more plainly. The material, when treated with the persulphate, has the appearance of being deeply etched.

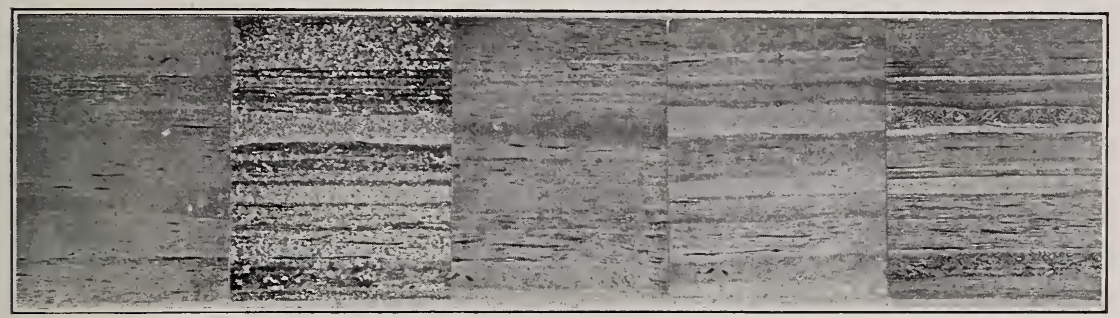

$\begin{array}{ccccc}a & b & c & d & e\end{array}$

FIG. 2.-Structure of "streaky" commercial wrought iron revealed by different etching reagents. $\times I$

The same specimen was used throughout. Etching reagents: $a, 2$ per cent alcoholic nitric acid; $b$, aqueous solution of ammonium persulphate; $c$, copper ammonium chloride (Heyn's reagent); $d$, acidified solution of copper chloride (Stead's reagent); $e$, hot concentrated hydrochloric acid, 5 minutes immersion

This is not so, however, as the etch pattern can be readily removed by rubbing the surface with emery flour. Fig. 2 represents the order in which the successive etchings of the specimen were carried out. In each case the previous etch pattern was removed by

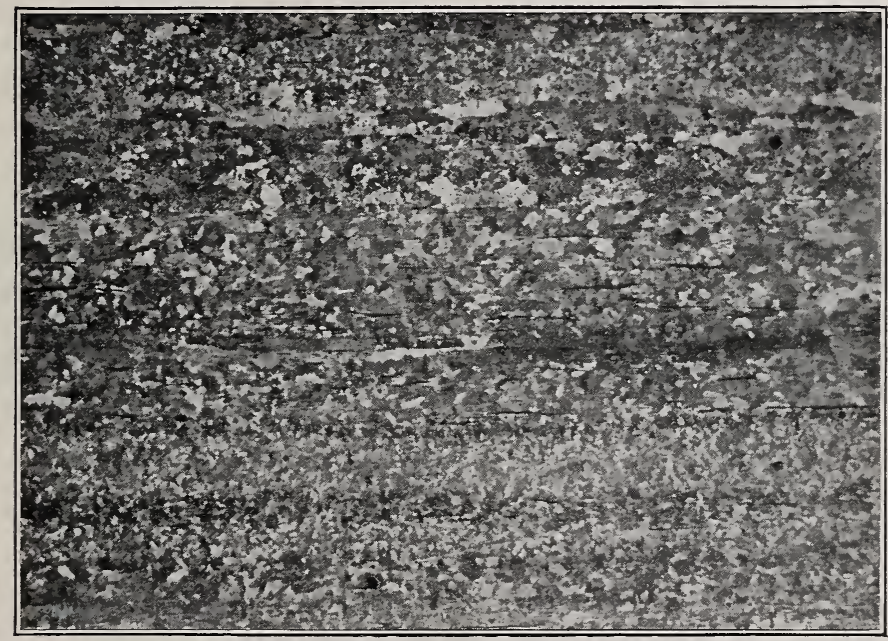

FIG. 3.-Crystalline structure of wrought iron revealed by etching with solution of ammonium persulphate. $\times 3$

The same specimen shown in Fig. 2 is here shown at a slightly higher magnification rubbing the surface with emery flour on the tip of the finger. It may be noted in passing that this is an excellent method for freeing the surface of a specimen from finger prints and other traces of oil or grease before etching the material. 


\section{CHEMICAL UNHOMOGENEITY}

One of the most useful purposes served by macroscopic etching is the revealing of chemical unhomogeneity; that is, variations in
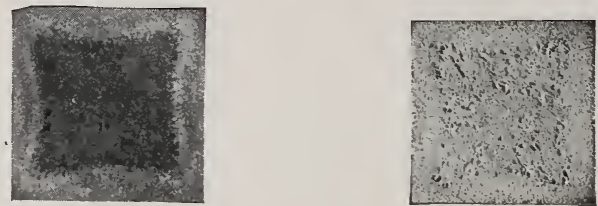

FIG. 4.-Chemical unhomogeneity in a bar of segregated steel as revealed by different methods of etching. X I

Etching reagents: $a$, aqueous solution of ammonium persulphate; $b$, hot concentrated hydrochloric acid

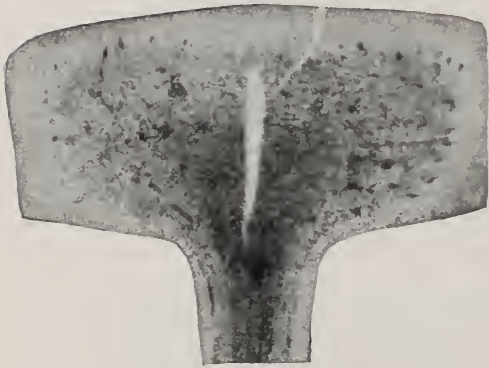

$a$

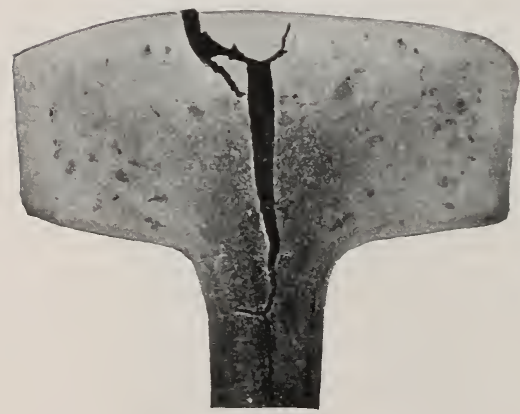

$c$

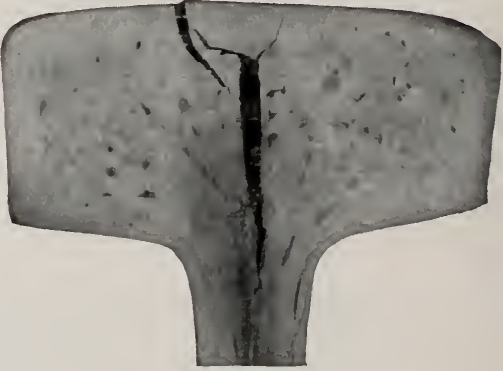

$b$

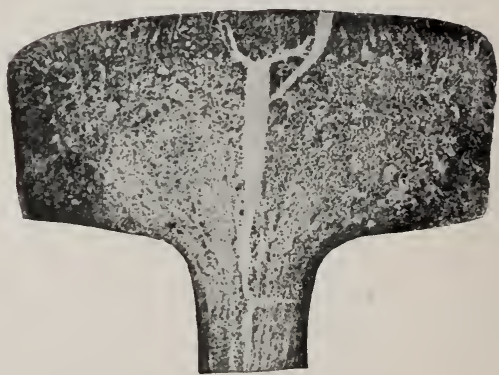

$d$

FIG. 5.-Chemical unhomogeneity in the head of a rail as revealed by different methods of etching. $\times 5 / 7$

Methods of etching: $a$, Sulphur print; $b$, copper ammonium chloride (Heyn's reagent); $c$, aqueous solution of ammonium persulphate; $d$, deeply etched in hot concentrated hydrochloric acid, inked with printer's ink, and a print made of the etched surface

chemical composition due to segregation, cementation, and other causes. Figs. 4 and 5 illustrate the fact that etching with persulphate is usually sufficient to reveal such differences in composition. 
The chemical analysis of segregated specimen shown in Fig. 4 . indicated that the central and outer portions of the bar differed principally in the sulphur and phosphorus content. The percentages were as follows: Phosphorus, outside 0.076 per cent, center 0.138 per cent; sulphur, outside 0.029 per cent, center 0.064 per cent. The appearance of the surface after deep etching in hot concentrated hydrochloric acid and that after etching with ammonium persulphate are quite similar.

Fig. 5 shows a section of the head of a segregated rail which failed in service. The use of several of the common etching reagents is illustrated. The zone of segregation, which is largely

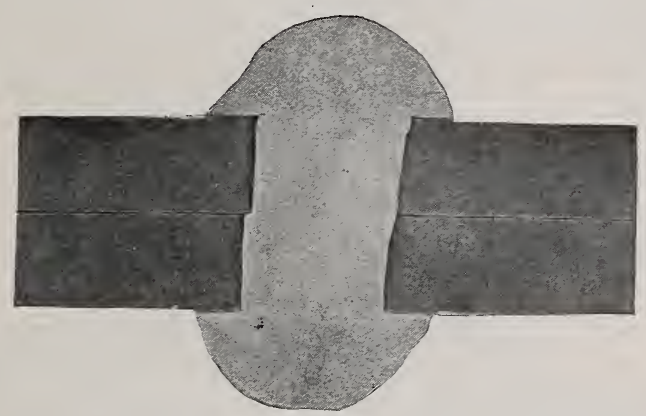

FIr. 6.-Differences in composition of steel rivet as compared with the nickel-steel riveted plates, revealed by etching with ammonium persulphate solution. $\times I$

due to sulphur as shown by Fig. $5 \mathrm{a}$, is quite definitely indicated by the persulphate etching.

Fig. 6 shows a section through a low carbon steel rivet which holds together two plates of $3^{1 / 2}$ per cent nickel steel. Only by etching with ammonium persulphate was it found possible to reveal any of the "flow lines" within the rivet. These are faintly shown in the figure. Other macroscopic etching methods showed only a difference in shade of the rivet as compared with the plates, indicating thus that the two differed very considerably in composition.

Variations in structural condition due to local heating, of parts of a steel specimen which may arise in such processes as welding, oxyacetylene cutting, etc., are also readily revealed by persulphate etching. Fig. 7 shows sections of the head of a steel rail to which a copper bonding cable has been welded at the side. The depth to which the metal has been affected by the heating 
is rendered plainly visible by etching with ammonium persulphate or with very dilute nitric acid.

\section{DISCUSSION AND SUMMARY}

It is evident from the foregoing discussion and results that ammonium persulphate is a very useful reagent for revealing the

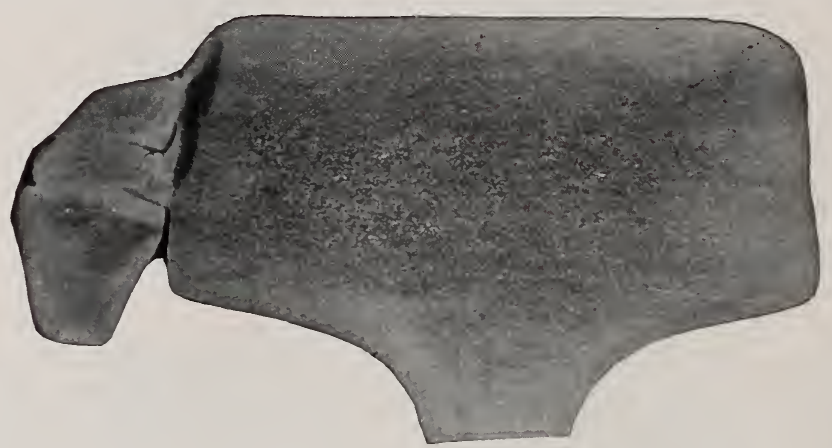

$a$

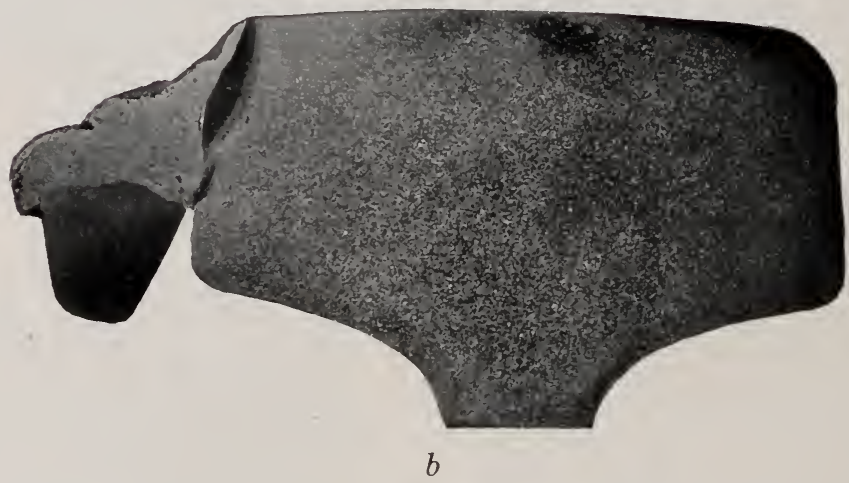

FIG. 7.-Structural changes caused by heat treatment incidental to welding operations as rezealed by different etching reagents $\times I$

The cross section of the rail head reveals the effect of the heating caused by welding on the copper bond at the side, $a$ and $b$ represent the same rail but different cross sections. Etching reagents: $a$, Aqueous solution of ammonium persulphate; $b, 2$ per cent alcoholic nitric acid

macrostructure of iron and steel. Its action depends primarily upon the formation of acid and the liberation of oxygen from the spontaneous decomposition of the salt upon the addition of water. It is to be recommended particularly for revealing the crystalline condition of iron and steel although chemical unhomogeneity is also indicated by its use. 
It is not to be inferred that the persulphate reagent is the only means by which crystalline heterogeneity may be revealed. Other methods, such as deep etching with concentrated acid, or by prolonged etching in dilute solutions-for instance, picric acidwill often reveal the same features. Such processes, however, are very tedious and time consuming and the face of the specimen becomes so roughened and pitted as to render it of no further value for examination without deeply grinding and repolishing the surface. In this way features close to the surface might be entirely removed between successive etchings.

The cleanliness of the persulphate reagent and the ease with which it may be applied even to surfaces of considerable size are also important factors favoring the use of this method of etching.

Washington, August 27, 1920. 




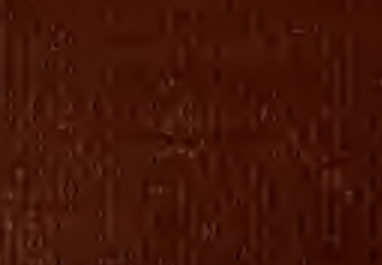

